\title{
Prototype Design Internet of Things Based Waste Management Using Image Processing
}

\author{
Mochammad Haldi Widianto ${ }^{1, *}$, Ari Purno Wahyu ${ }^{2}$, Dadan Gusna ${ }^{2}$ \\ ${ }^{1}$ Informatics Departement, School of Computer Science, Bina Nusantara University, Jakarta, Indonesia 11480 \\ ${ }^{2}$ Informatics Departement, Faculty of Engineering Widyatama University, Bandung, 40125, Indonesia
}

\begin{tabular}{l} 
A R T I C L E I N F O \\
\hline Article history: \\
Received: 26 January, 2021 \\
Accepted: 08 March, 2021 \\
Online: 20 March, 2021
\end{tabular}

Keywords:

Waste Management

Sorting

Iot

Image Processing

\begin{abstract}
A B S T R A C T
Waste is currently a serious problem often found in rural areas, rural areas, and even industrial areas. Waste is a side effect of activities carried out by humans to meet social or industrial needs. Increasing human productivity will also increase the amount of waste produced. To overcome this, a sorting management system is needed. Good waste is seen from the processing method to the recycling process. The waste management problem still relies on the old system transporting and disposing of waste to the final disposal site (TPA). The TPA itself sometimes piles up in one place so that the waste process becomes uneven and the sorting process is not good, causing type waste. This accumulates and mixes with other hazardous waste. In today's modern era, the management and sorting system is the same. Object detection and waste classification are carried out in the Sensor system to introduce the previously prepared model. The prototype article recognition model is prepared with waste images to produce a freeze forecast graph used for object discovery which is carried out via the camera associated with the Arduino Uno as the basic unit handling. Ultrasonic sensors are inserted into each garbage compartment to filter out the refill filling rate. The sorting system itself can use computer-based image processing methods. Image Processing is used to process data in real-time and fill the trash level. The sensor module that is implanted to detect waste management personnel, the results of this study prove that image management can accommodate waste particles and tested in the BlackBox method produces results following the required quantitative with the accuracy in both the camera, sensor, and image process used can detect an average of $70 \%$.
\end{abstract}

\section{Introduction}

Currently, waste can be referred to as the effect of activities carried out by urban or rural communities. Waste is a waste product or a used product that is not produced. This residual product has less benefit compared to the product used, so the residual effect is discarded or not reused. Various types of waste are called Solid Waste. Garbage is divided into two types, namely organic waste and non-organic waste. Organic waste is waste that can be broken down, such as food scraps. Leaves, and wood, while non-organic, are waste that cannot be decomposed but can be recycled, such as plastic, glass, paper, and metal waste. This waste will be a disaster for human life and the environment if it is not appropriately managed so that a sorting system and good processing to reduce the effects and side effects for the environment are needed $[1,2]$.

${ }^{*}$ Corresponding Author: Mochammad Haldi Widianto, Kecamatan Buah Batu, Bandung, Indonesia, mochamad.widianto@binus.ac.id
While human waste (human waste) is commonly utilized for stomach-related items, the human can be a genuine wellbeing danger since it can be used as a vector (implies of advancement) for infections caused by infections and microbes. One of the advances in diminishing infection transmission through human squanders with a clean and sterile way of life. A sound sanitation system cannot be separated from the regulation. Some examples of waste generated in households include waste from batteries, electric lights, electronics, pesticide packaging, clothes bleach, floor cleaners, paint, pressure cans (aerosol), fuel packaging, leftover medicines (pharmaceuticals), mercury thermometer, and syringes. The ingredients contained therein have characteristics that can cause harm to human safety and health and environmental pollution $[3,4]$.

Waste management is an excessive activity as it takes up a lot of assets and work. The specialists have endeavored to improve the board frameworks by setting up the recyclable canister and 
dispatching the 3 Rs lobby (recycle, reuse and reduce). At the same time, the problem currently faced is waste disposed of either by home or industry. It is still mixed and has not been correctly sorted. For example, the household waste itself has dangerous substances such as high-pressure aerosol cans, waste liquid, and pharmaceutical drug remnants, this type of waste will become toxic. Some of the items can be flammable, which is dangerous for cleaners and the surrounding environment. Current waste sorting system technology has offered various solutions, including the use of technology-based electronic sensors [5].

Information is a component of the IoT needed in communicating because several main elements must be known in communicating on IoT devices, namely the communicator, listener, and information message. Further processing of data that already has added value or, in other words, information is data that has been classified or processed or interpreted for use in the decision-making process. The communication system used can be a GSM module to transmit data from sensors to the clouds in the form of a web-based $[6,7]$.

There was no tool for sorting waste into certain parts in previous research due to inadequate waste processing factors. This study focuses on processing waste sorting by utilizing computer vision $[8,9]$ and sorting management where data processing is accurate and very suitable for placing on other large machines. It is hoped that this tool can help several dumpsites $[10,11]$.

\section{Related Work}

With the uneven development of Internet of Things (IoT) arrangements comes the more major worry over security issues related to most gadgets. It is extended that the product on the Internet of things related gadgets will surpass 20 Billion devices by $2020[12,13]$. A considerable lot of these arrangements will use and using cell association availability to interconnect. An inadequately architected cell network can open the answer for potential security issues. A profoundly gotten compositional understanding requires a multilayered security approach enveloping the by and large building plan for the web, traversing from the edge gadget as far as possible up to the objective host for preparing, stockpiling, and further use.[14-16].

For an IoT-based answer to being actualized, it ought to be energy effective, ready to impart and share data across broadened inclusion. An IoT-based installed framework is proposed in [17]. GSM correspondence innovation is utilized as the stage to perform information transmission to the worker. In [18], a keen container framework dependent on AI, picture handling, and IoT is proposed. This framework utilizes a convolutional neural organization $(\mathrm{CNN})$ to distinguish and isolate squander into various classes, like metal, glass, paper, and plastic. A sum of 400 to 500 pictures containing the four unique types is utilized to prepare the organization [19].

The IoT device has a central control system or what is called a microcontroller [20,21]. A microcontroller is a computer system built on a single chip and a processor used for control purposes. Even though it has a much smaller form than a personal computer and the mainframe computer, the microcontroller is built from the same essential elements. One of the microcontrollers often used is the Arduino Uno $[22,23]$. The system utilizes Raspberry Pi 3 and Xilinx PYNQ-Z1 FPGA board and pre-trained ResNet-34, a convolution neural organization containing 34 pre-trained layers to perform gathering. The data accumulated from the canister is sent utilizing a LoRa correspondence arrange from a sensor center to the section.

Arduino is a microcontroller development board based on Arduino using the Atmega2560 chip. This board is total, has everything required for a microcontroller. With primary usage, the researcher has to connect the control from USB to PC or via a connector. The following is a table of specifications from the Arduino Mega [24, 25]. Another sensor that is used to monitor the volume of the trash can is ultrasonic. The working principle of the HCSRF-04 Ultrasonic Sensor is a transmitter that sends an ultrasonic wave which is then measured by the time it takes until the reflection of the object arrives. The length of time is proportional to twice the distance between the sensor and the object [26-28]. because there are many types of microcontrollers, the image below is the result of how the microcontroller diagram works.

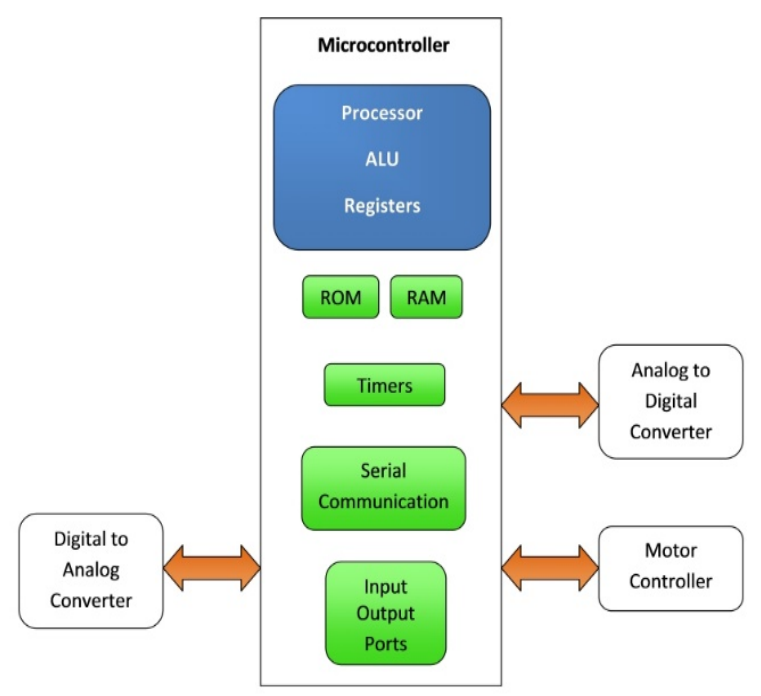

Figure 1: Microcontroller Diagram

In a waste bin, waste is divided into two parts, namely solid and liquid waste. Liquid waste is a type of waste that is dangerous because it can seep into the ground and will affect air quality, so detection is necessary for the trash. This liquid waste uses a ph Meter sensor. The sensor will deal with the edge of waste and go into protected or dangerous conditions. Next, the $\mathrm{pH}$ meter comprises an anode (estimating test) conveyed to an electronic gadget that measures and shows the $\mathrm{pH}$ esteem.

The main working principle of a $\mathrm{pH}$ meter lies on the sensor probe in the form of a glass electrode by measuring the number of $\mathrm{H} 3 \mathrm{O}+$ ions in a solution. The tip of the glass electrode is $0.1 \mathrm{~mm}$ thick round glass. By using a layer (bulb), this tool is paired with an elongated non-conducting glass or plastic cylinder, which is then filled with $\mathrm{HCl}$. In the $\mathrm{HCl}$ solution, a long silver electrode wire is immersed on the surface that compounds the $\mathrm{AgCl}$ balance.

The constant amount of $\mathrm{HCl}$ solution in this system makes the $\mathrm{Ag} / \mathrm{AgCl}$ electrode has a stable potential value. The $\mathrm{pH}$ sensor core is on the surface of a glass ball which can exchange positive 
ions $(\mathrm{H}+)$ with a measured solution. The things above that can help in the sorting process into the TPA (final disposal site). With the help of existing sensors. It is also our contribution because, in previous studies, there has not been any research until the landfill $[29,30]$.

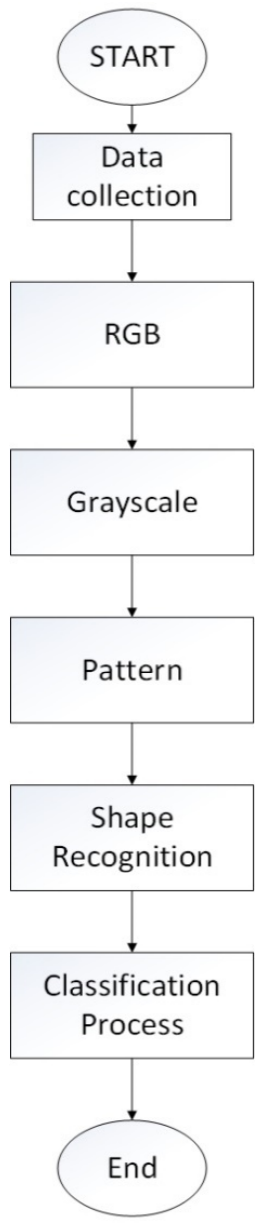

Figure 2: Methods used in image processing

\section{Research Methodology}

Based on several literature studies, a sorting system can be combined with a hardware device or device, these devices include infrared sensors and metal detection sensors which are commonly used, identification of the types of metal and non-metal waste itself functions to facilitate the sorting process as well as the plastic and paper waste separation system and another method is the use of image processing, this system is beneficial when sorting in visual form, an application that has a reliable level of intelligence is needed in sorting waste types so that the sorting method with image processing techniques and IOT combinations becomes a solution and help choose the type of waste and its characteristics $[31,32]$.

Before creating a sorting system, a grouping of the kinds of waste is needed. It is necessary because the type of waste itself has different effects and characters. It is based on the type and area of waste found. In contrast, the most recent waste is toxic waste and is very dangerous to human health and the environment. Based on this problem, a reliable sorting system is needed. This research has reviewed IoT-based waste processing technology. It can be combined with the sensor to detect the presence or absence of a toxic substance. Toxic substances in the waste are carried out by a sensor sorting the use of image processing technology to detect the categorization of types of waste [33, 34].

Figure 2 analyzes the waste image images and sorts them by several stages. First, data collection is carried out. The researcher in this section looks for the pictures needed as a database. Second and third image processing is done into RGB and Grayscale to assist in the image processing process. Fourth, image processing is carried out by looking for patterns from the image. Fifth, the result of the pattern obtained is the recognition of the shape of the image, which will be used for classification at a later stage. The last is to determine the classification to determine whether the image is as desired and looking at the resulting accuracy, the resulting accuracy will explain in the last section. [35].

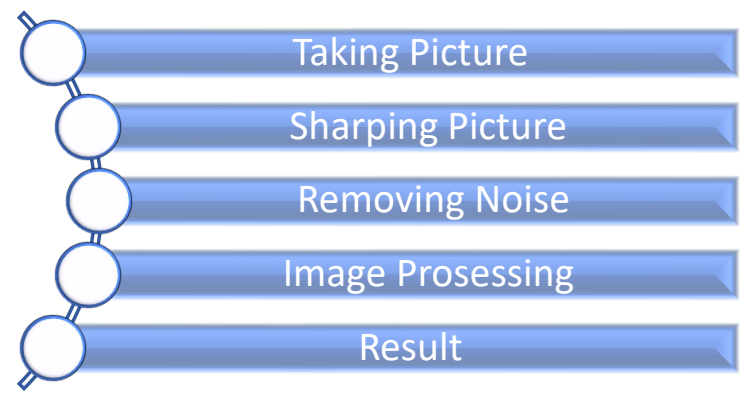

Figure 3: Our Research Methodology

Figure 3 is our sequences of this research as explained below:

- Taking Picture

In this process, taking pictures can be using a mobile device or a camera mounted on a conveyor machine. The camera is endeavored to have a high image capture capability so that the accuracy of the object taken has a high reading data precision.

- Sharping Picture

In this process, image sharpening reduces accuracy if the object is taken in a low light condition. The image processing algorithm has a high reading accuracy and can sharpen the item to be processed.

- Removing Noise

Removing vandalism or distracting light objects can result in decreased accuracy of per-item readings. In this process, the worrying process will be eliminated by the system.

- Image Processing the object reading process is performed by distinguishing the objects read by the system. It can be determining the color of the texture, the shape of the item, the data of each object will be converted into binary numbers. After That stored in the database as training data, the amount of training data using plastic, metal waste samples, cans, and organic.

- Result

In this process, the system will display and classify several types of waste into metal and non-metal waste and classify it into organic and non-organic waste[36, 37]. 
In this method, a sorting system is performed using image processing techniques. This method has reliability in recognizing an object and has been implemented in various fields. This system also has a level of accuracy and can be used to sort waste by type and size. In general, the current sorting system using a conveyor machine is used to sort metal and non-metal waste, which in turn serves to facilitate the process of smelting and recycling. This conveyor system works by reading sensors installed on the sorting machine. Sensors that are often used are usually humidity sensors, heavy sensors, and solenoids to detect metals. This system can detect and classify types of waste but still has the disadvantage of distinguishing types of waste based on the form of waste and the presence or absence of hazardous chemicals in the waste. This must be overcome so that a manual sensor is needed that is combined with imaging techniques and is equipped with image processing. So it can endanger hazardous chemicals in treated waste. Another thing that causes the spread of toxic substances in a waste to be detected. The space of chemicals can be very dangerous and visible, especially in waste-making materials that contain metals.

Sampling data for training is more than 5000 garbage data collected. The amount of data is a data collection standard used to identify types of organic and non-organic waste. The garbage data is then converted into a binary number which represents an assessment of the type and color of the object. After that, it will then be seen visually by the system.

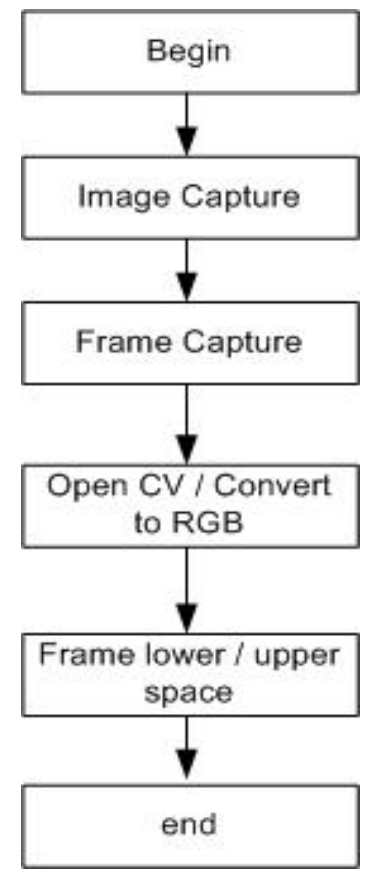

Figure 4: Pseudocode RGB \& Color conversation

Figure 4 above is the process of image conversion using python and the NumPy library. The script above shows that the captured image will be converted to RGB format for each picture frame. The image is then converted to $100 \times 100$ pixels, which is the size set for
255 as the largest size. This method serves to calibrate the image size and the selected object to be determined.

In this study, researchers used a BlackBox to measure the success of the prototype quantitatively. By understanding the black box, the resercher can interpret the model, know the role of each layer, as well understand the stupid side of the model made.

\section{Result}

The following is a display of the results of the UI / UX program from the IoT application program for the efficiency of trash cans and the results of implementing an image-based process.

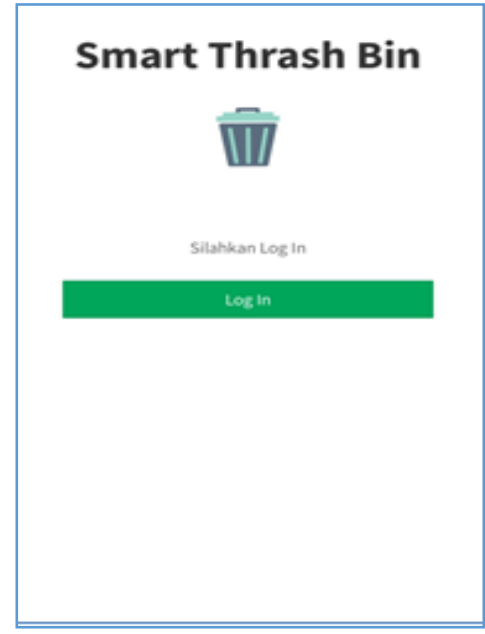

Figure 5: Trash bin login system

Figure 5 above is a place sorting system that is integrated with mobile devices. In this application, there are additional security features that are used for login validation. It uses an email data recognition system and can manage more than one trash can area.

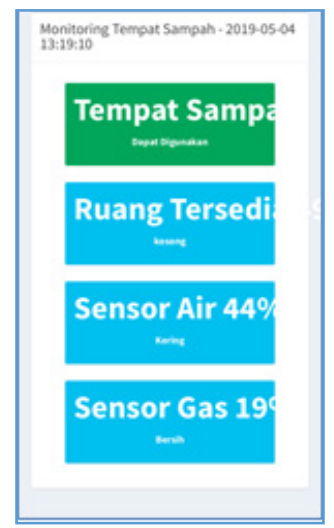

Figure 6: Trash bin login system

Figure 6 above shows how the gas sensor works, which will forward the data taken from the sensor installed on the smart trash bin. The sensor sends data via clouds and is displayed from the mobile device in a website application. The sensor data will automatically be monitored by the system and displayed changes every time depending on the amount of waste available. 


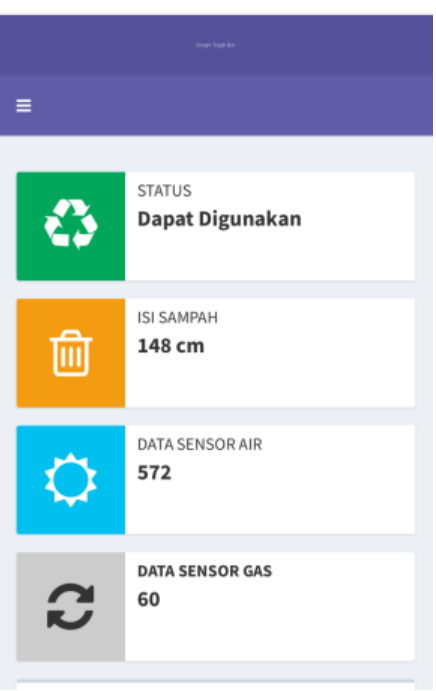

Figure 7: Overall monitoring system

Figure 7 is the overall data monitoring system. Four components are monitored, namely;

- $\quad$ Trash bin status

The same place has two monitoring conditions that can be used and are not ready to be used. If it is full, then the trash cannot be used and is in a full state until it exceeds the trash bin's capacity limit.

- The number of contents in the trash bin

The second component is measuring trash bins based on the number of bins with a capacity of up to $180 \mathrm{~cm}$ high and then filled with $148 \mathrm{~cm}$. Based on this data, the trash cans are still in use.

- Liquid sensor data

This type of detectable waste has two types of solid and liquid. Waste in liquid form has high toxicity and can damage other waste. This sensor will detect a lot of waste in liquid form, and the system will provide information if the $\mathrm{pH}$ meter of liquid waste exceeds normal limits.

- Gas sensor data

The last sensor is a gas sensor. This sensor will detect the presence of waste and hazardous chemicals in the trash. Hazardous chemicals can cause poisoning to fires that can endanger the surrounding environment. The smart trash bin has menu information that can see the condition of the trash that is full. After that, toxic gas is also measured. This sensor is located on the lid of the trash because harmful gases are lighter and more comfortable to detect.

The waste sorting system has a function to process images to select two types of waste, organic and non-organic. This system uses a computer vision method where waste data will be recognized and identified according to the type of waste. Make this system, and waste type data must be collected first by dividing the research data into two, namely in the training data mode and data testing.

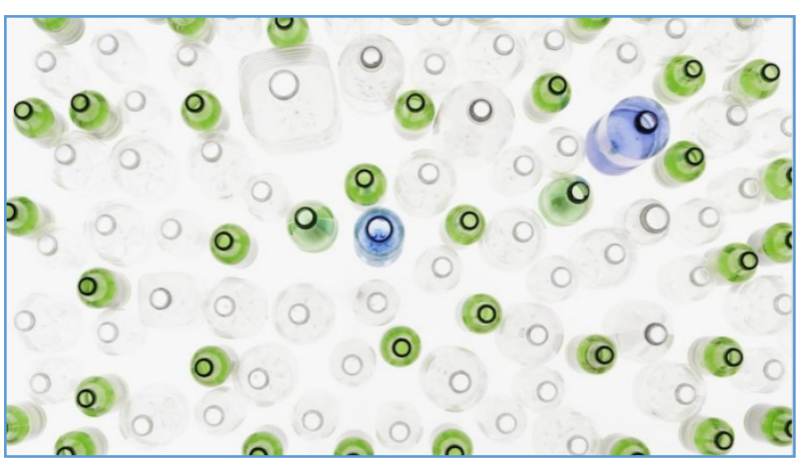

Figure 8: Process of Taking Pictures of Plastic Waste

Figure 8 is an image-based sorting system used as a processing material for the sorting system, as training data for the author to take image data from various sources on the Internet. Direct image taking requires additional lighting and tools because the image processing system itself depends on the camera's reliability.

Data reading and accuracy on the amount of training data and testing data used. The type of algorithm selection is very influential on the pattern recognition method. This method dramatically determines the speed and accuracy of data reading.

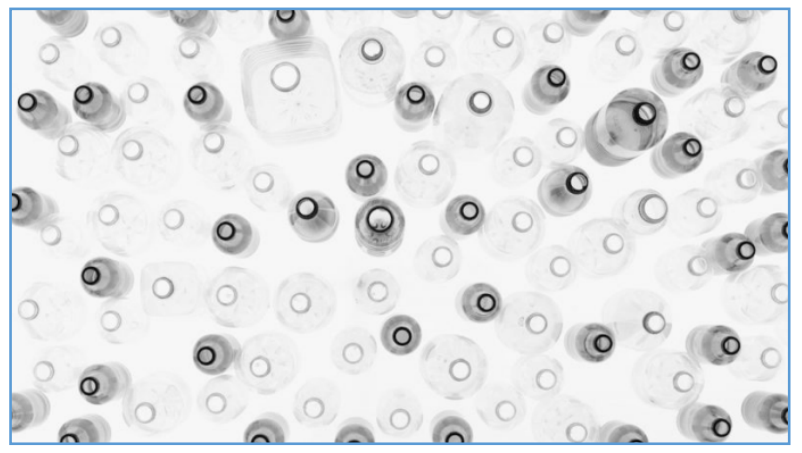

Figure 9: Greyscale Image Change Process

Figure 9 is a method for changing the color from the original RGB image to greyscale. This process is needed to identify plastic bottles and glass bottles because the white color in an image processing will be converted to zero (0) and black with a value of one (1). , so that one of the plastic bottle sorting systems apart from the color will also be read. From its shape by using the edge detection method, in this section, the data information from the glass plastic bottle will be taken through the level of additional lighting so that the nuances of the resulting data color become gray or also called by the achromatic method.

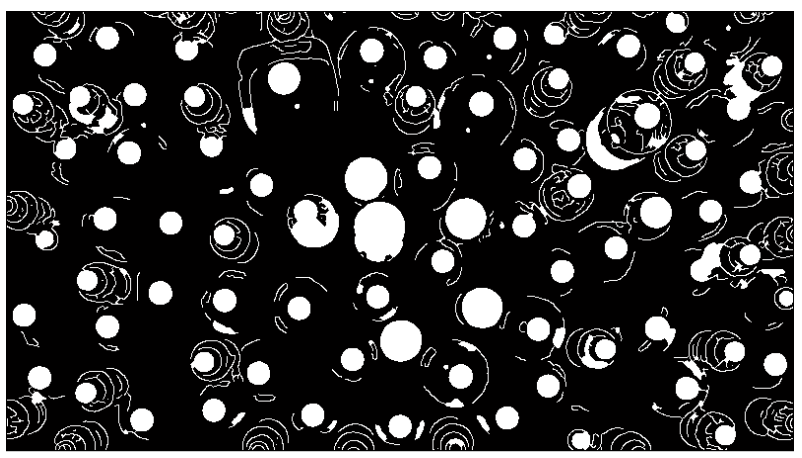

Figure 10: process of detecting patterns, shapes, edges, and colors 
Figure 10 is an essential step because an object, in this case, a plastic bottle and glass bottle, will be processed and recognized again by detecting its shape, then clicking the edges to see the type of characteristics of the bottle.

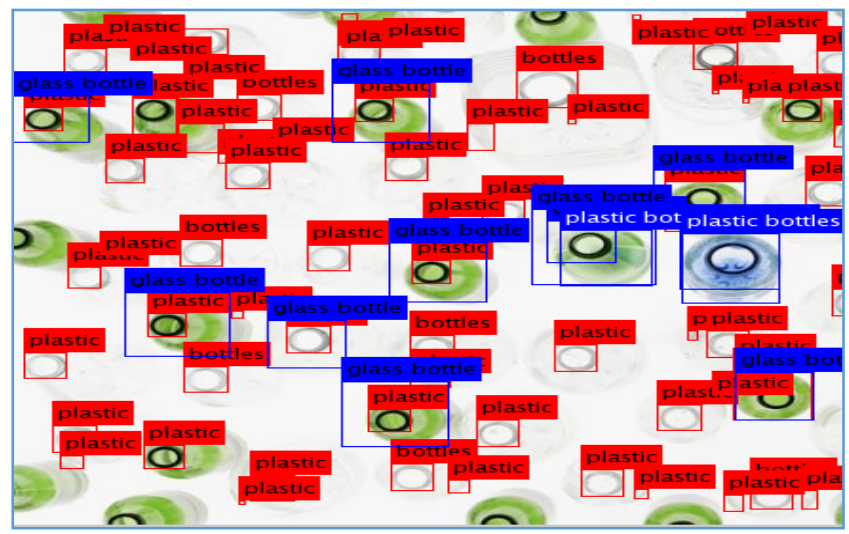

Figure 11: The final result of the plastic waste identification

Figure 11 is the final result of the plastic waste detection system. that image the system visually provides information on the type of plastic waste. This case is divided into various kinds of plastic bottle waste and glass bottle waste. The sorting procedure is carried out quickly by the system using image processing algorithms.

To see the results based on the Blackbox, here is a quantitative measurement of the results of this study.

Table 1: Arduino camera functions based on the distance of the trash

\begin{tabular}{|l|l|l|}
\hline No & \multicolumn{1}{|c|}{ Distance } & \multicolumn{1}{|c|}{$\begin{array}{c}\text { Detected / } \\
\text { Undetected }\end{array}$} \\
\hline 1 & $0 \mathrm{~cm}$ & Detected \\
\hline 2 & $4 \mathrm{~cm}$ & Detected \\
\hline 3 & $5 \mathrm{~cm}$ & Detected \\
\hline 4 & $5.5 \mathrm{~cm}$ & Detected \\
\hline 5 & $6 \mathrm{~cm}$ & Detected \\
\hline 6 & $10 \mathrm{~cm}$ & Detected \\
\hline 7 & $40 \mathrm{~cm}$ & UnDetected \\
\hline
\end{tabular}

Table 2: Ultrasonic functions based on the distance of the trash

\begin{tabular}{|l|l|l|}
\hline No & \multicolumn{1}{|c|}{ Distance } & \multicolumn{1}{|c|}{$\begin{array}{c}\text { Detected / } \\
\text { Undetected }\end{array}$} \\
\hline 1 & $0 \mathrm{~cm}$ & Detected \\
\hline 2 & $4 \mathrm{~cm}$ & Detected \\
\hline 3 & $5 \mathrm{~cm}$ & Detected \\
\hline 4 & $5.5 \mathrm{~cm}$ & Detected \\
\hline 5 & $6 \mathrm{~cm}$ & Detected \\
\hline 6 & $10 \mathrm{~cm}$ & UnDetected \\
\hline 7 & $40 \mathrm{~cm}$ & UnDetected \\
\hline
\end{tabular}

Table 3: Accuracy Testing Results

\begin{tabular}{|l|l|l|}
\hline No & \multicolumn{1}{|c|}{ Image Name } & \multicolumn{1}{c|}{ Accuracy } \\
\hline 1 & Image1 & $70 \%$ \\
\hline 2 & Image2 & $68 \%$ \\
\hline 3 & Image3 & $73 \%$ \\
\hline 4 & Image4 & $75 \%$ \\
\hline 5 & Image5 & $79 \%$ \\
\hline
\end{tabular}

The results according to table 1-3 show that the functionality of the prototype is fairly good because the accuracy in both the camera, sensor, and image process used can detect an average of $70 \%$.

\section{Conclusion}

In the experiment, the waste processing process using several technologies by using IoT (Internet of Things) using image processing methods. IoT systems are very suitable for use outdoors and mounted on a sensor. This sensor is straightforward to configure and integrate with the system. Website application, the IoT sensor has the advantage of being able to detect the type of waste in the form of liquids and gases, which functions to detect waste and hazardous substances. In contrast, the image processing method has reliability. Can detect types of waste by recognizing types of waste. Image processing techniques can run in various programming languages and types of platforms. Image processing is fully available in the form of platform libraries in all programming languages. Also, the output system can assign classes to objects, and to use the image processing method can be used to detect the type of metal or non-metallic waste according to the dataset used as needed. The results also show, from the side of the tool, it can detect waste. While the image imaging process where the prototype is capable of with an average accuracy of $70 \%$. For further investigations, it is hoped that it can be checked not only in the form of a prototype but also in the form of a device with a detection result above $90 \%$.

\section{References}

[1] R. Nadaf, V. Bonal, "Smart Mirror using Raspberry Pi as a Security and Vigilance System," 2019 3rd International Conference on Trends in Electronics and Informatics (ICOEI), (Icoei), 360-365, 2019, doi:10.1109/icoei.2019.8862537.

[2] M. Hamza, S.A. Lohar, S. Ghulamani, A. Shah, "Smart Mirror for Home and Work Environment," 1-4, 2020, doi:10.1109/icetas48360.2019.9117296.

[3] S. Sharma, A. Sharma, T. Goel, R. Deoli, S. Mohan, "Smart Home Gardening Management System: A Cloud-Based Internet-of-Things (IoT) Application in VANET," 2020 11th International Conference on Computing, Communication and Networking Technologies, ICCCNT 2020, 2020, doi:10.1109/ICCCNT49239.2020.9225573.

[4] G. Hristov, J. Raychev, D. Kinaneva, P. Zahariev, "Emerging Methods for Early Detection of Forest Fires Using Unmanned Aerial Vehicles and Lorawan Sensor Networks," 2018 28th EAEEIE Annual Conference, EAEEIE 2018, 1-9, 2018, doi:10.1109/EAEEIE.2018.8534245.

[5] P.N. Saranu, G. Abirami, S. Sivakumar, K.M. Ramesh, U. Arul, J. Seetha, "Theft Detection System using PIR Sensor," Proceedings of the 4th International Conference on Electrical Energy Systems, ICEES 2018, 656660, 2018, doi:10.1109/ICEES.2018.8443215.

[6] M.H. Widianto, R. Aryanto, C. Fadillah, "Multi-antenna spectrum sensing using bootstrap on cognitive radio for internet of things application," 
International Journal of Recent Technology and Engineering, 8(3), 26202624, 2019, doi:10.35940/ijrte.C4928.098319.

[7] M.H. Widianto, Ranny, N.F. Thejowahyono, S.B. Handoyo, "Internet of things based on smart mirror to improve interactive learning," International Journal of Emerging Trends in Engineering Research, 8(9), 4900-4907, 2020, doi:10.30534/ijeter/2020/02892020.

[8] H.B. Kekre, T.K. Sarode, F. Ansari, "Performance evaluation of DCT, Walsh, Haar and Hartley transforms on whole images and partial coefficients in Image Classification," Proceedings - 2012 International Conference on Communication, Information and Computing Technology, ICCICT 2012, 16, 2012, doi:10.1109/ICCICT.2012.6398176.

[9] Y. Suzuki, M. Mitsukawa, K. Kawagoe, "A image retrieval method using TFIDF based weighting scheme," Proceedings - International Workshop on Database and Expert Systems Applications, DEXA, 112-116, 2008, doi:10.1109/DEXA.2008.106.

[10] I. Slonkina, M. Kupriyashin, G. Borzunov, "Analysis and optimization of the packing tree search algorithm for the knapsack problem," Proceedings of the 2019 IEEE Conference of Russian Young Researchers in Electrical and Electronic Engineering, ElConRus 2019, 1811-1815, 2019, doi:10.1109/EIConRus.2019.8657309.

[11] T. Nguyen, N. Tran, L. Loven, J. Partala, M.T. Kechadi, S. Pirttikangas, "Privacy-aware blockchain innovation for 6G: Challenges and opportunities," 2nd 6G Wireless Summit 2020: Gain Edge for the 6G Era, 6G SUMMIT 2020, 1-5, 2020, doi:10.1109/6GSUMMIT49458.2020.9083832.

[12] S. Elmeadawy, R.M. Shubair, "6G Wireless Communications: Future Technologies and Research Challenges," 2019.

[13] A. Yastrebova, R. Kirichek, Y. Koucheryavy, A. Borodin, A. Koucheryavy, "Future Networks 2030: Architecture Requirements," International Congress on Ultra Modern Telecommunications and Control Systems and Workshops, 2018-Novem, 1-8, 2019, doi:10.1109/ICUMT.2018.8631208.

[14] D.A. Alboaneen, D. Alsaffar, A. Alateeq, A. Alqahtani, A. Alfahhad, B. Alqahtani, R. Alamri, L. Alamri, "Internet of Things Based Smart Mirrors: A Literature Review," ICCAIS 2020 - 3rd International Conference on Computer Applications and Information Security, (1), 2020, doi:10.1109/ICCAIS48893.2020.9096719.

[15] Y. Sun, L. Geng, K. Dan, "Design of Smart Mirror Based on Raspberry Pi," Proceedings - 3rd International Conference on Intelligent Transportation, Big Data and Smart City, ICITBS 2018, 2018-Janua, 77-80, 2018, doi:10.1109/ICITBS.2018.00028.

[16] W. Xi, E.W. Patton, "Block-Based Approaches to Internet of Things in MIT App Inventor."

[17] J. Kokila, K. Gayathri Devi, M. Dhivya, C.N. Haritha Jose G P, "Design and Implementation of IoT Based Waste Management System," Middle-East Journal of Scientific Research, 25(5), 995-1000, 2017, doi:10.5829/idosi.mejsr.2017.995.1000.

[18] K.S. Hulyalkar S., Deshpande R., Makode K., "Implementation of Smartbin Using Convolutional Neural Networks," International Research Journal of Engineering and Technology, 5(4), 3352-3358, 2018.

[19] D. Ziouzios, M. Dasygenis, "A Smart Recycling Bin for Waste Classification," 5th Panhellenic Conference on Electronics and Telecommunications, PACET 2019, 1-4, 2019, doi:10.1109/PACET48583.2019.8956270.

[20] M.H. Widianto, A. Darisman, "Water Monitoring and Automatic Feed in Aquarium Based on Microcontroller," International Journal of Engineering and Advanced Technology, 9(2), 1738-1743, 2019, doi:10.35940/ijeat.b2506.129219.

[21] M.H. Widianto, R. Aryanto, C. Fadillah, "Multi-antenna spectrum sensing using bootstrap on cognitive radio for internet of things application," International Journal of Recent Technology and Engineering, 8(3), 2019, doi:10.35940/ijrte.C4928.098319.

[22] K.N. Hairol, R. Adnan, A.M. Samad, F. Ahmat Ruslan, "Aquaculture Monitoring System using Arduino Mega for Automated Fish Pond System Application," Proceedings - 2018 IEEE Conference on Systems, Process and Control, ICSPC 2018, (December), 218-223, 2019, doi:10.1109/SPC.2018.8704133.

[23] R.M. Kingsta, A.S. Saumi, P. Saranya, "Design and construction of arduino based $\mathrm{pH}$ control system for household waste water reuse," Proceedings of the International Conference on Trends in Electronics and Informatics, ICOEI 2019, (Icoei), 1037-1041, 2019, doi:10.1109/ICOEI.2019.8862752.

[24] I.S. Akila, P. Karthikeyan, H.M.V. Hari, K.J. Hari, "IoT Based Domestic Fish Feeder," Proceedings of the 2nd International Conference on Electronics, Communication and Aerospace Technology, ICECA 2018, (Iceca), 1306-1311, 2018, doi:10.1109/ICECA.2018.8474829.

[25] L. Goswami, M.K. Kaushik, R. Sikka, V. Anand, K. Prasad Sharma, M. Singh Solanki, "IOT Based Fault Detection of Underground Cables through

www.astesj.com
Node MCU Module," 2020 International Conference on Computer Science, Engineering and Applications, ICCSEA 2020, 2020, doi:10.1109/ICCSEA49143.2020.9132893.

[26] M. Sheth, P. Rupani, "Smart Gardening Automation using IoT with BLYNK App," Proceedings of the International Conference on Trends in Electronics and Informatics, ICOEI 2019, 2019-April(Icoei), 266-270, 2019, doi:10.1109/icoei.2019.8862591.

[27] F. Khan, A.U. Rehman, M.A. Jan, I.U. Rahman, "Efficient resource allocation for real time traffic in cognitive radio internet of things," Proceedings - 2019 IEEE International Congress on Cybermatics: 12th IEEE International Conference on Internet of Things, 15th IEEE International Conference on Green Computing and Communications, 12th IEEE International Conference on Cyber, Physical and So, 1143-1147, 2019, doi:10.1109/iThings/GreenCom/CPSCom/SmartData.2019.00193.

[28] W. Yang, H. Wang, "Application of electrical capacitance tomography in pharmaceutical manufacturing processes," I2MTC 2019 - 2019 IEEE International Instrumentation and Measurement Technology Conference, Proceedings, 2019-May, 1-6, 2019, doi:10.1109/I2MTC.2019.8826945.

[29] N. Jia, C. Zheng, "Design of Intelligent Medical Interactive System Based on Internet of Things and Cloud Platform," Proceedings - 2018 10th International Conference on Intelligent Human-Machine Systems and Cybernetics, IHMSC 2018, 1, 28-31, 2018 , doi:10.1109/IHMSC.2018.00015.

[30] M.S. Hadi, P. Adi Nugraha, I.M. Wirawan, I. Ari Elbaith Zaeni, M.A. Mizar, M. Irvan, "IoT Based Smart Garden Irrigation System," 4th International Conference on Vocational Education and Training, ICOVET 2020, 361-365, 2020, doi:10.1109/ICOVET50258.2020.9230197.

[31] Z. Kato, T. Kato, N. Kondo, T. Orii, "Interstitial deletion of the short arm of chromosome 10: Report of a case and review of the literature," Japanese Journal of Human Genetics, 41(3), 333-338, 1996, doi:10.1007/BF01913177.

[32] J. Zhu, M. Zhao, S. Zhang, W. Zhou, "Exploring the Road to 6G : ABC Foundation for Intelligent Mobile Networks," 51-67, 2019.

[33] V.C. Pinto, P.J. Sousa, V.H. Magalhães, C.F. Araújo, G. Minas, M. Luís, "COST-EFECTIVE LAB-ON-A-CHIP DEVICE FOR SEAWATER PH QUANTIFICATION BY OPTICAL METHODS Microelectromechanical Systems Research Unit ( CMEMS - UMinho ), University of Minho Campus de Azurém, Guimarães, Portugal Design and fabrication of the microfluidic di," (June), 2266-2269, 2019.

[34] K. Drivers, C. Requirements, S. Architectures, "6G Technologies: Key Drivers, Core Requirements, System Architectures, and Enabling Technologies," IEEE Vehicular Technology Magazine, PP, 1, 2019, doi:10.1109/MVT.2019.2921398.

[35] K. Chen, Y. Cheng, H. Bai, C. Mou, Y. Zhang, "Research on Image Fire Detection Based on Support Vector Machine," 2019 9th International Conference on Fire Science and Fire Protection Engineering, ICFSFPE 2019, (51578464), 1-7, 2019, doi:10.1109/ICFSFPE48751.2019.9055795.

[36] C. Geng, S. Qu, Y. Xiao, M. Wang, G. Shi, T. Lin, J. Xue, Z. Jia, "Diffusion mechanism simulation of cloud manufacturing complex network based on cooperative game theory," Journal of Systems Engineering and Electronics, 29(2), 321-335, 2018, doi:10.21629/JSEE.2018.02.13.

[37] F. Guerriero, R. Guido, G. Mirabelli, V. Solina, "Supporting a Pharmaceutical Wholesaler in the Vehicle Fleet Organization: An Italian Case Study," Proceedings of the 2019 10th IEEE International Conference on Intelligent Data Acquisition and Advanced Computing Systems: Technology and Applications, IDAACS 2019, 2, 765-768, 2019, doi:10.1109/IDAACS.2019.8924417. 